\section{EDUCAÇÃO INFANTIL E FORMAÇÃO DOCENTE: ANÁLISE DAS EMENTAS E BIBLIOGRAFIAS DE DISCIPLINAS DOS CURSOS DE EDUCAÇÃO FÍSICA}

\author{
EARLY CHILDHOOD EDUCATION AND TEACHERS' TRAINING: ANALYSIS OS \\ SYLLABI AND BIBLIOGRAPHIES OF COURSES IN PHYSICAL EDUCATION \\ SCHOOLS
}

\author{
EDUCACIÓN INFANTIL Y FORMACIÓN DOCENTE: ANÁLISIS DE LOS \\ CONTENIDOS Y BIBLIOGRAFÍAS DE DISCIPLINAS DE LOS CURSOS DE \\ EDUCACIÓN FÍSICA
}

\section{Rodrigo Lema Del Rio Martins*, Luiza Fraga Tostes*, André da Silva Mello*}

\begin{abstract}
Palavras chave: Educação Infantil. Capacitação de professores. Ementas. Bibliografia.

Resumo: 0 objetivo da pesquisa é analisar as ementas e bibliografias de disciplinas relacionadas a Educação Infantil nos cursos de formação inicial em Educação Física, identificando os pontos de convergência e de divergência que elas estabelecem com os documentos norteadores dessa primeira etapa da Educação Básica no Brasil. Trata-se de uma pesquisa documental, realizada com 16 ementas e suas respectivas bibliografias (267) de 14 cursos de Educação Física de universidades públicas do país. Os dados foram sistematizados pelo software Iramuteq. Constata-se que a concepções de infância e de organização do trabalho pedagógico presentes nas ementas e bibliografias divergem dos pressupostos preconizados pelas Diretrizes Curriculares Nacionais para a Educação Infantil e pela Base Nacional Curricular Comum. Nos documentos analisados predomina uma visão biologicista/universal de desenvolvimento infantil, amparada por autores da Psicologia do Desenvolvimento e do Comportamento Motor.
\end{abstract}

\begin{abstract}
This study looks into syllabi and bibliographies courses related to Early Childhood Education in the initial training courses in Physical Education, identifying their points of convergence and divergence with guiding documents of that first stage of Elementary Education in Brazil. It is a documentary study conducted on 16 syllabi and their respective bibliographies (267) of 14 Physical Education Schools of public universities. Data were systematized by the Iramuteq software. Conceptions of childhood and organization of pedagogical work present in the analyzed syllabi and bibliographies differ from the assumptions recommended by the National Curriculum Guidelines for Early Childhood Education and by the National Curricular Common Base. A biologic/universal vision of child development prevails in the documents analyzed, based on Developmental Psychology and Motor Behavior authors.
\end{abstract}

Palabras clave: Educación Infantil. Capacitación de profesores. Contenidos. Bibliografía.
Resumen: El objetivo de la investigación es analizar los contenidos y bibliografías de disciplinas relacionadas con Educación Infantil en los cursos de formación inicial en Educación Física, identificando los puntos de convergencia y de divergencia que establecen con los documentos orientadores de la primera etapa de la Educación Básica en Brasil. Se trata de una investigación documental realizada con los contenidos de 16 materias y sus respectivas bibliografías (267) de 14 cursos de Educación Física de universidades públicas del país. Los datos fueron sistematizados por el software Iramuteq. Se constata que la concepción de infancia y de organización del trabajo pedagógico presentes en los contenidos y bibliografías analizados divergen de los presupuestos preconizados por las Directrices Curriculares Nacionales para la Educación Infantil y por la Base Nacional Curricular Común. En los documentos analizados predomina una visión biologicista/universal de desarrollo infantil, amparada por autores de la Psicología del Desarrollo y del Comportamiento Motor.
*Universidade Federal do Espírito Santo. Vitória, ES, Brasil. E-mail: rodrigoefrural@ hotmail.com; lufragatostes@gmail.com; andremellovix@gmail.com.

Recebido em: 23-10-2017 Aprovado em: 20-04-2018

DOI: https://doi.org/10.22456/1982-8918.77519 (c) (1) () Licence 


\section{INTRODUÇÃO}

A relação entre a Educação Física e a Educação Infantil tem se manifestado em diferentes dimensões, mobilizando pesquisadores a analisarem a inserção dessa área do conhecimento na primeira etapa da Educação Básica (CAVALARO; MULLER, 2009; RICHTER; VAZ, 2010); questões relativas à formação docente (AYOUB, 2001; PINTO, 2001; LACERDA; COSTA, 2012; MARTINS, 2015; SAYÃO, 1999); e as práticas pedagógicas desenvolvidas nesse contexto (DEBORTOLI, 2008; KLIPPEL, 2013; MELLO; SANTOS, 2012).

No tocante à formação docente, Sayão (1999) afirma que os cursos de licenciatura em Educação Física não priorizam a preparação de professores para atuar na Educação Infantil. Para Ayoub (2001), os currículos dos cursos de formação inicial em Educação Física não consideram as especificidades da Educação Infantil e as singularidades das crianças pequenas. Segundo Martins (2015), ainda prevalecem representações e práticas na Educação Infantil que concebem as crianças como seres incompletos, incapazes de pensar e agir sobre si mesmos.

As Diretrizes Curriculares Nacionais para a Educação Infantil (DCNEI) (BRASIL, 2013) defendem que as crianças sejam consideradas como sujeitos de direitos, produtoras de cultura e protagonistas dos seus próprios processos de socialização. As DCNEI concebem a formação docente como elemento primordial na construção de uma proposta pedagógica de qualidade que atenda às especificidades das crianças pequenas, garantindo as experiências estéticas por meio da sensibilidade, da criatividade, da ludicidade e da liberdade de expressão na produção das culturas infantis (BRASIL, 2013).

A efetivação de práticas pedagógicas que caminhem nessa direção requer a ampliação de estudos que problematizem a atuação dos professores de Educação Física com a pequena infância, pautados nas concepções e pressupostos que atualmente balizam a organização legal e pedagógica da primeira etapa da Educação Básica, expressas tanto nas DCNEI quanto na Base Nacional Comum Curricular (BNCC) (BRASIL, 2016). A predileção por utilizar esses documentos como referências leva em consideração que eles dialogam com os movimentos do componente curricular e com a produção acadêmico-científica da Educação Física na Educação Infantil (MELLO et al., 2016).

Por outro lado, notamos a carência de pesquisas que investiguem os processos de formação inicial em Educação Física voltada para a atuação profissional na Educação Infantil. Levantamento realizado em seis importantes periódicos científicos ${ }^{1}$ da área revela que, entre 1979 e 2015, há apenas três artigos dedicados a essa temática.

A Educação Física é o segundo maior curso formador de professores no país, ultrapassando a marca de 185.000 matrículas no ano de 2016, ficando atrás, somente, da Pedagogia (INEP, 2016). O Brasil conta, atualmente, com 752 cursos de licenciatura em Educação Física em atividade espalhados por todo o território nacional, nas cinco regiões geográficas, sendo 367 situados nas capitais, ou seja, 48,8\% do total (e-MEC, 2017). ${ }^{2}$

Ainda, segundo a plataforma e-MEC, no Brasil existem 308 instituições públicas de Ensino Superior, sendo 76 municipais, 124 estaduais e 108 federais. Destas, 82 oferecem o curso de licenciatura em Educação Física (três municipais, 30 estaduais e 49 federais), representando $26,62 \%$ do total. As capitais brasileiras concentram 34 cursos de licenciatura em Educação Física $(41,5 \%)$ em instituições públicas de Ensino Superior (9 estaduais e 25 federais).

1 Movimento, Revista Brasileira de Ciência do Esporte, Motriz, Revista de Educação Física da UEM, Pensar a Prática e Revista Brasileira de Educação Física e Esporte.

2 E-MEC: Sistema de Regulação do Ensino Superior. Disponivel em: <http://emec.mec.gov.brl>. Acesso em: 21 mar. 2017. 
Nesse contexto, faz-se necessário compreender como os currículos das licenciaturas em Educação Física das universidades públicas do país têm abordado questões referentes à organização e à operacionalização do trabalho pedagógico com a Educação Infantil. Uma das maneiras de averiguar como este tema tem sido tratado é analisando as ementas e as bibliografias das disciplinas curriculares da Educação Física que tematizam a Educação Infantil. Assim, é possível captar indícios sobre as concepções e os pressupostos que ancoram essas disciplinas, pois as ementas se caracterizam como uma descrição que resume o conteúdo conceitual de uma determinada disciplina curricular, enquanto as bibliografias relacionam as obras que dão suporte teórico-metodológico a essas disciplinas.

Portanto, o objetivo deste artigo é analisar as ementas e bibliografias de disciplinas relacionadas à Educação Infantil nos cursos de formação inicial em Educação Física, identificando os pontos de convergência e de divergência que elas estabelecem com os documentos norteadores dessa primeira etapa da Educação Básica no Brasil, que apontam para o reconhecimento da criança como sujeito de direitos, produtora de cultura e protagonista em seus processos de socialização.

\section{PERCURSO TEÓRICO-METODOLÓGICO}

Trata-se de uma pesquisa documental, que utiliza como fontes as ementas e as bibliografias das disciplinas relacionadas à Educação Infantil dos cursos regulares, presenciais e com pelo menos uma turma já graduada em licenciatura em Educação Física de universidades públicas do país, sediadas nas capitais brasileiras em que há a presença de professores de Educação Física atuando na primeira etapa da Educação Básica pública municipal. ${ }^{3}$

Escolhemos as universidades públicas devido às pesquisas desenvolvidas por essas instituições no contexto nacional e pela influência regional que elas exercem na formação docente nas cidades e nos estados em que estão sediadas. 0 recorte pelas capitais leva em conta a sua capacidade de propagação das políticas públicas - entre elas as educacionais para outras cidades, bem como prováveis parcerias pontuais e/ou mais duradouras, que as universidades costumam estabelecer com o poder público, a fim de oportunizar campos de pesquisa, ensino e extensão, promovendo a aproximação e a interlocução entre os sujeitos da Universidade e da Educação Básica.

De acordo com a plataforma e-MEC, ${ }^{4}$ são 19 universidades públicas brasileiras que se enquadram no critério definido para este estudo. ${ }^{5}$ As ementas e as bibliografias foram acessadas nos sites oficiais das instituições, por meio de telefonemas e/ou por mensagens eletrônicas (e-mail) às coordenações de curso. A única instituição da qual não obtivemos informações foi a IFRR, por essa razão, ela foi excluída das análises.

\footnotetext{
3 Belém/PA, Brasília/DF, Boa Vista/RR, Campo Grande/MS, Cuiabá/MT, Florianópolis/SC, João Pessoa/PB, Manaus/AM, Palmas/TO, Porto Alegre/RS, Recife/PE, Rio de Janeiro/RJ e Vitória/ES. Todas as secretarias municipais de educação de capitais brasileiras foram consultadas por telefone e/ou por correio eletrônico (e-mail) entre os meses de agosto e outubro de 2016.

4 Nessa base de dados, é possível consultar as informações sobre as Instituições de Ensino Superior e sobre os cursos de graduação reconhecidos pelo Ministério da Educação em todo território nacional. Disponível em: <http://emec.mec.gov.br/>. Acesso em: 21 abr. 2017.

5 Universidade Federal do Rio Grande do Sul (UFRGS), Universidade Federal de Santa Catarina (UFSC), Universidade para o Desenvolvimento do Estado de Santa Catarina (UDESC), Universidade Federal do Rio de Janeiro (UFRJ), Universidade Estadual do Rio de Janeiro (UERJ), Universidade Federal do Espírito Santo (UFES), Universidade de Brasília (UnB), Universidade Federal do Mato Grosso (UFMT), Universidade Federal do Mato Grosso do Sul (UFMS), Universidade Federal de Pernambuco (UFPE), Universidade Federal Rural de Pernambuco (UFRPE), Universidade Estadual de Pernambuco (UPE), Universidade Federal da Paraíba (UFPB), Universidade Federal do Pará (UFPA), Universidade Estadual do Pará (UEPA), Universidade Estadual de Roraima (UERR), Instituto Federal de Roraima (IFRR), Universidade Federal do Amazonas (UFAM), Universidade Estadual do Amazonas (UEA). Embora Palmas/TO seja uma capital brasileira que tem a presença de professores de Educação Física atuando na Educação Infantil pública municipal, a Universidade Federal de Tocantins (UFT) não possui o curso de licenciatura em Educação Física em Palmas, apenas em cidades do interior como Miracema/TO e Tocantinópolis/TO, e o Instituto Federal do Tocantins (IFTO) só possui o curso iniciado em 2015 na modalidade PARFOR (Programa Nacional de Formação de Professores de Educação Básica), portanto, sem nenhuma turma formada ainda.
} 
O corpus deste estudo é constituído por 16 ementas que focalizam questões relacionadas às práticas pedagógicas e 267 obras vinculadas a elas, entre artigos, documentos oficiais, livros, capítulos de livros, teses e dissertações. No processo de análise utilizamos 0 software Iramuteq ${ }^{6}$ (CAMARGO; JUSTO, 2013) para realizar um tratamento quali-quantitativo aos dados que, depois de processados, foram analisados por meio da nuvem de palavras e pela análise de similitudes.

A nuvem de palavras agrupa as palavras e as organiza graficamente em função da sua frequência. Cabe ressaltar que o software Iramuteq só faz registro das palavras que foram mencionadas pelo menos três vezes no corpus textual examinado. A análise de similitudes está ancorada na teoria dos grafos (elementos combinatórios) e permite identificar as co-ocorrências entre as palavras e a conexidade que há entre elas, auxiliando na identificação da estrutura do texto (CAMARGO; JUSTO, 2013). Esses métodos combinados contribuem para compreender quais são as tendências, características e ausências de itens lexicais no material analisado.

No processo de análise dos dados, estabelecemos diálogos entre as ementas e as bibliografias. O software permitiu produzir uma metanálise dos documentos trabalhados, ou seja, realizar uma análise geral do corpus textual utilizado em um quadro interpretativo mais amplo, sem entrar nas especificidades de cada ementa/bibliografia. Para exemplificar as categorias analíticas produzidas, recorremos a alguns excertos de ementas.

\section{APRESENTAÇÃO E ANÁLISE DOS DADOS}

No Quadro1, a seguir, apresentamos as universidades e as disciplinas de onde foram extraídas as ementas e bibliografias trabalhadas neste estudo:

Quadro 1 - Universidades e disciplinas que abordam a Educação Infantil

\begin{tabular}{|c|l|}
\hline INSTITUIÇÃO & \\
\hline UFAM & Educação Física na infância \\
\hline UERR & Prática profissional I \\
\hline UPE & $\begin{array}{l}\text { Fundamentos teórico-metodológicos da Educação Física na Educação Infantil e no } \\
\text { Ensino Fundamental I }\end{array}$ \\
\hline UFPE & Metodologia do ensino da Educação Física I \\
\hline UFPB & Educação física infantil \\
\hline UnB & $\begin{array}{l}\text { Educação Física na Educação Infantil } \\
\text { Prática de Ensino 1 }\end{array}$ \\
\hline UFMT & Prática curricular na Educação Física Infantil \\
\hline UFMS & Educação Física na Educação Básica I \\
\hline UERJ & $\begin{array}{l}\text { Prática em Educação Física Escolar I } \\
\text { Educação Física Escolar infantil }\end{array}$ \\
\hline UFRJ & Educação Física na Educação Infantil \\
\hline UFES & Educação Física na Educação Infantil \\
\hline UDESC & Educação Física Escolar I \\
\hline UFSC & Educação Física na infância \\
\hline UFRGS & Fundamentos da Educação Física na Educação Infantil \\
\hline
\end{tabular}

Fonte: Os autores.

6 Software gratuito e com fonte aberta, desenvolvido pelo Prof. Dr. Pierre Ratinaud, do Laboratório de Estudos e Pesquisas Aplicadas em Ciências Sociais, da Universidade de Toulouse III, que realiza análises sobre corpus textuais. Essas análises têm várias finalidades, sendo possível examinar textos, entrevistas, documentos, redações, etc. 
Das 18 universidades pesquisadas, em 14 delas encontramos disciplinas específicas sobre a Educação Infantil. Em duas universidades (UFPA e UEA), não achamos nenhuma disciplina específica e, em outras duas (UEPA e UFRPE), encontramos apenas o Estágio Supervisionado voltado para a Educação Infantil. Por isso, elas foram descartadas deste estudo. Os textos completos das ementas e os autores presentes nas bibliografias foram inseridos, separadamente, no software Iramuteq, que gerou uma nuvem de palavras específica para as ementas e outra para as bibliografias. Devido à natureza do material, a análise de similitudes só foi gerada para análise das ementas. Para formar a nuvem de palavras, foram codificados todos os textos das ementas na íntegra e o último sobrenome dos autores das bibliografias. A Imagem 1, a seguir, apresenta a nuvem de palavras gerada a partir das ementas selecionadas:

Imagem 1 - Ementas

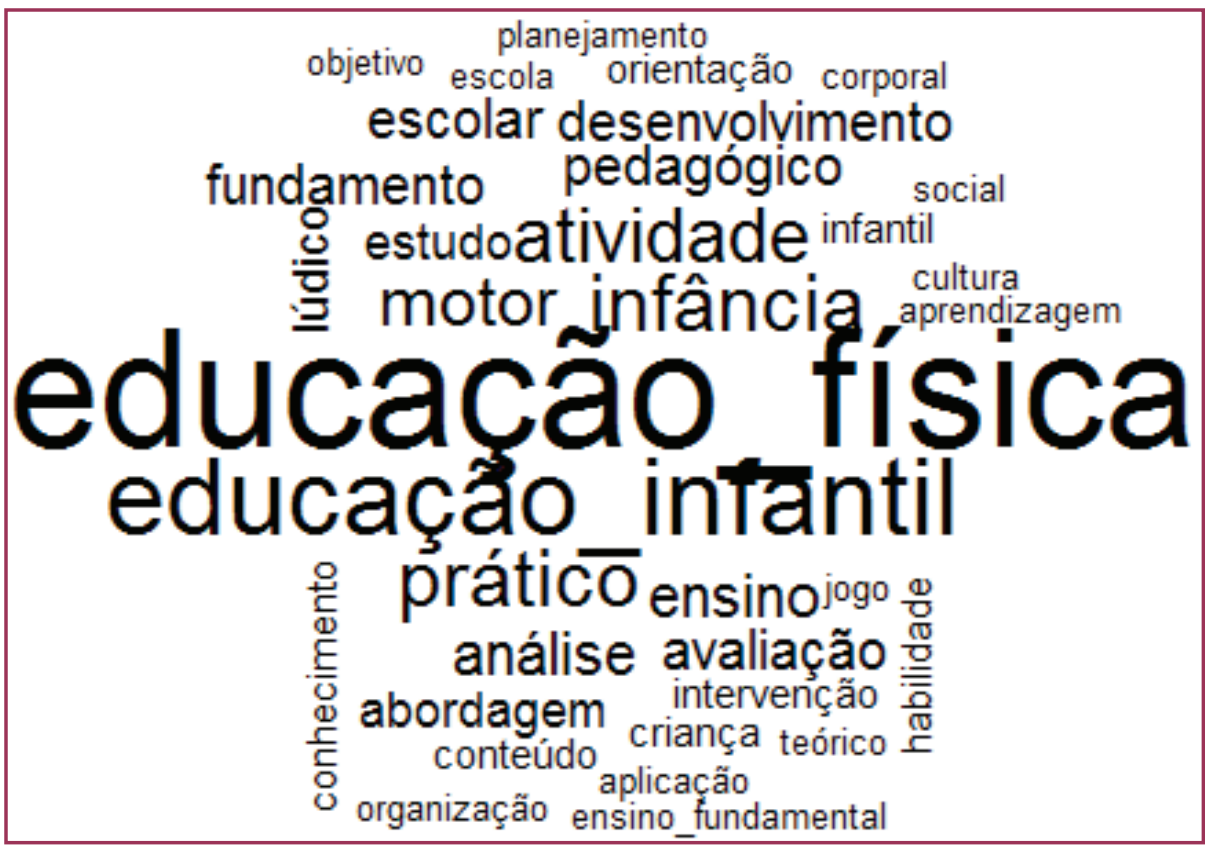

Fonte: Os autores.

As palavras mais recorrentes nas ementas aparecem em maior tamanho e centralizadas. Já as palavras com menor incidência aparecem na periferia da nuvem e com um tamanho menor. As palavras Educação Física (23 menções) e Educação Infantil (14 menções) se destacam face ao recorte que foi efetuado na seleção das disciplinas que, justamente, previa a articulação entre esses dois campos. As outras palavras presentes na nuvem denotam uma série de conexões assentadas na forma de organização do trabalho pedagógico e nos pressupostos que orientam as disciplinas. Só é possível compreender as conexões que essas palavras estabelecem entre si por meio da análise de similitudes, demonstrada na Imagem 2 (na próxima página).

A Análise de Similitudes das ementas demonstra que as conexões entre as palavras formam quatro blocos temáticos, são eles: didático-pedagógico; dimensão conceitual do conhecimento; comportamento motor; e dimensão cultural. Para produzir inferências sobre esses blocos, utilizamos excertos das ementas. 
Imagem 2 - Análise de similitudes de palavras presentes nas ementas

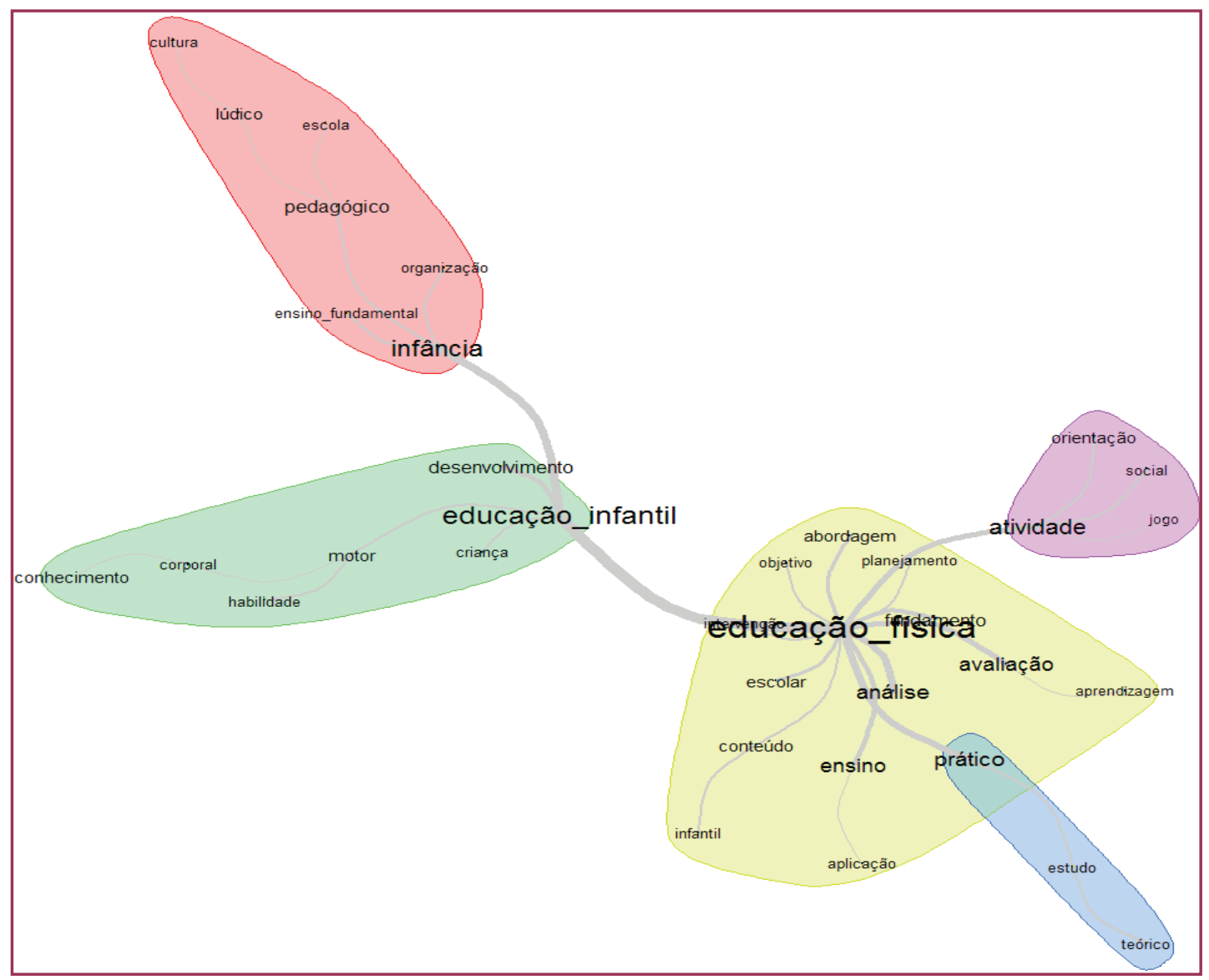

Fonte: Os autores.

No bloco didático-pedagógico, estão agrupadas as seguintes palavras: prático (10), ensino (7), avaliação (6), pedagógico (6), intervenção (4), orientação (4), aplicação (3), planejamento (3) e organização (3). Essas palavras expressam a preocupação das disciplinas analisadas com a sistematização do conhecimento e com a sua operacionalização educativa. Elas estão associadas ao termo Educação Física e aparecem concentradas na região amarela da Análise de Similitudes. Os seguintes excertos denotam o caráter de organização didáticopedagógico presente nas ementas:

Aplicação de conhecimentos teórico-práticos adquiridos nas disciplinas de graduação como exercício de docência em escolas da rede pública de ensino; mecanismos operacionais e técnicas específicas utilizadas na intervenção do magistério em Educação Física (PRÁTICA DE ENSINO I - UnB).

Análise, seleção e organização de propostas pedagógicas de Educação Física para a Educação Infantil (EDUCAÇÃO FíSICA NA EDUCAÇÃO BÁSICA I-UFMS).

Propõe a elaboração e aplicação de planos de ensino de Educação Física em turmas de educação infantil. (FUNDAMENTOS DA EDUCAÇÃO FÍSICA NA EDUCAÇÃO INFANTIL - UFRGS).

Suporte à prática de ensino aprendizagem da Educação Física. Estudo da avaliação e aprendizagem da Educação Física (METODOLOGIA DO ENSINO DA EDUCAÇÃO FÍSICA I - UFPE).

A dimensão didático-pedagógica é fundamental na organização da prática docente. Todavia, essa dimensão não é neutra e isenta da concepção de homem, de sociedade e de educação que a orienta. Nesse sentido, não encontramos evidências que sinalizem uma 
organização didático-pedagógica atrelada às especificidades da organização curricular da Educação Infantil e às singularidades das crianças, sobretudo, no que concerne à valorização do seu protagonismo e das suas produções culturais.

O bloco dimensão conceitual do conhecimento é composto pelas seguintes palavras: abordagem (4), estudo (4), fundamento (4), conhecimento (3), conteúdo (4) e teórico (3). As ementas enfatizam conhecimentos de natureza teórico-metodológica, como evidenciam os seguintes excertos:

Discute as abordagens pedagógicas que orientam a prática educativa nesse nível de ensino (FUNDAMENTOS DA EDUCAÇÃO FÍSICA NA EDUCAÇÃO INFANTIL - UFRGS).

Estudo dos fundamentos teóricos que dão suporte à prática de ensino aprendizagem da Educação Física (METODOLOGIA DO ENSINO DA EDUCAÇÃO FÍSICA I UFPE).

Abordagens teórico-metodológicas da Educação Física na Infância (EDUCAÇÃO FÍSICA NA INFÂNCIA - UFSC).

Estudo contextualizado de fundamentos teóricos e de documentos referenciais da educação para a infância (Educação Física na Educação Infantil - UnB).

Esse bloco valoriza o saber-objeto (CHARLOT, 2000). Nessa figura do aprender, a relação com o saber é de natureza epistêmica, uma relação de apropriação cognitiva, na qual são mobilizados conteúdos intelectuais. De certa forma, o que caracteriza a formação acadêmica é o diálogo com os conhecimentos científicos historicamente acumulados. Entretanto, esses conhecimentos não podem prescindir da permanente interação com a prática social, para que, em um movimento dialético, possam ser ressignificados e para que ressignifiquem a própria prática docente, superando, dessa forma, a dicotomia entre teoria e prática.

No bloco comportamento motor estão reunidas as palavras infância (10), motor (8), desenvolvimento (6), criança (4), habilidade (4) e corporal (3), que se associam à palavra Educação Infantil. As conexões que essas palavras estabelecem entre si sinalizam abordagens centradas no campo do Comportamento Motor, que é constituído pelas subáreas do Desenvolvimento Motor, da Aprendizagem Motora e do Controle Motor, como demonstram os seguintes excertos:

Habilidades motoras fundamentais. Níveis de desempenho e alterações de padrões motores na infância. Componentes de aptidão física e motora. Desenvolvimento motor-perceptivo na infância. Atividades motoras apropriadas às características, físicas, cognitivas, motoras, afetivas e sociais das crianças (EDUCAÇÃO FÍSICA INFANTIL - UFPB).

Aborda o ensino das habilidades motoras fundamentais, jogos, atividades rítmicas e ginástica no contexto da educação infantil. Estuda a avaliação do crescimento corporal e das capacidades coordenativas (FUNDAMENTOS DA EDUCAÇÃO FÍSICA NA EDUCAÇÃO INFANTIL - UFRGS).

A Educação Física e sua importância para o desenvolvimento infantil. (EDUCAÇÃO FÍSICA NA INFÂNCIA - UFAM).

O campo do Comportamento Motor apresenta importantes contribuições para as práticas pedagógicas da Educação Física com a Educação Infantil, especialmente na faixa etária de zero a três anos de idade, período em que os fatores maturacionais são preponderantes nos processos de desenvolvimento e aprendizagem. Todavia, apenas os conhecimentos 
oriundos desse campo são insuficientes para abarcar a complexidade do comportamento infantil, principalmente quando a concepção de infância adotada valoriza a centralidade das crianças nos processos pedagógicos empreendidos. Isso não significa que esse conhecimento é "descartável", mas que ele precisa dialogar com outros campos do conhecimento.

O bloco dimensão cultural é constituído pelas palavras cultura (4), lúdico (3) e social (3). Contrabalanceando a ênfase dada à dimensão biológica, as palavras desse bloco valorizam os aspectos socioculturais nas práticas pedagógicas. Os excertos de ementas, apresentados a seguir, demonstram como as palavras desse bloco estão articuladas:

Análise dos espaços e da cultura lúdica com ênfase nas possibilidades participativas, críticas e expressivas (EDUCAÇÃO FÍSICA NA INFÂNCIA - UFSC).

Atividades de integração e socialização com enfoque lúdico (PRÁTICA EM EDUCAÇÃO FÍSICA ESCOLAR I - UERJ).

História da infância, família e contexto sociocultural (EDUCAÇÃO FíSICA NA EDUCAÇÃO INFANTIL - UFRJ).

Toda prática social é, necessariamente, cultural. Portanto, imbricada por um conjunto de significados que conferem sentido à ação humana. No caso da Educação Infantil, as práticas pedagógicas da Educação Física necessitam dialogar com os elementos culturais, lúdicos e sociais que fazem parte do cotidiano das crianças e de suas famílias, consolidando, assim, ações socialmente referenciadas. Tais práticas buscam superar narrativas que homogeneízam sujeitos e instituições presentes em contextos complexos e multifacetados.

A Imagem 3, a seguir, apresenta a nuvem de palavras proveniente das bibliografias presentes nos documentos pesquisados. Por meio dela, é possível constatar os referenciais que dão suporte às disciplinas analisadas:

Imagem 3 - Nuvem de palavras das bibliografias

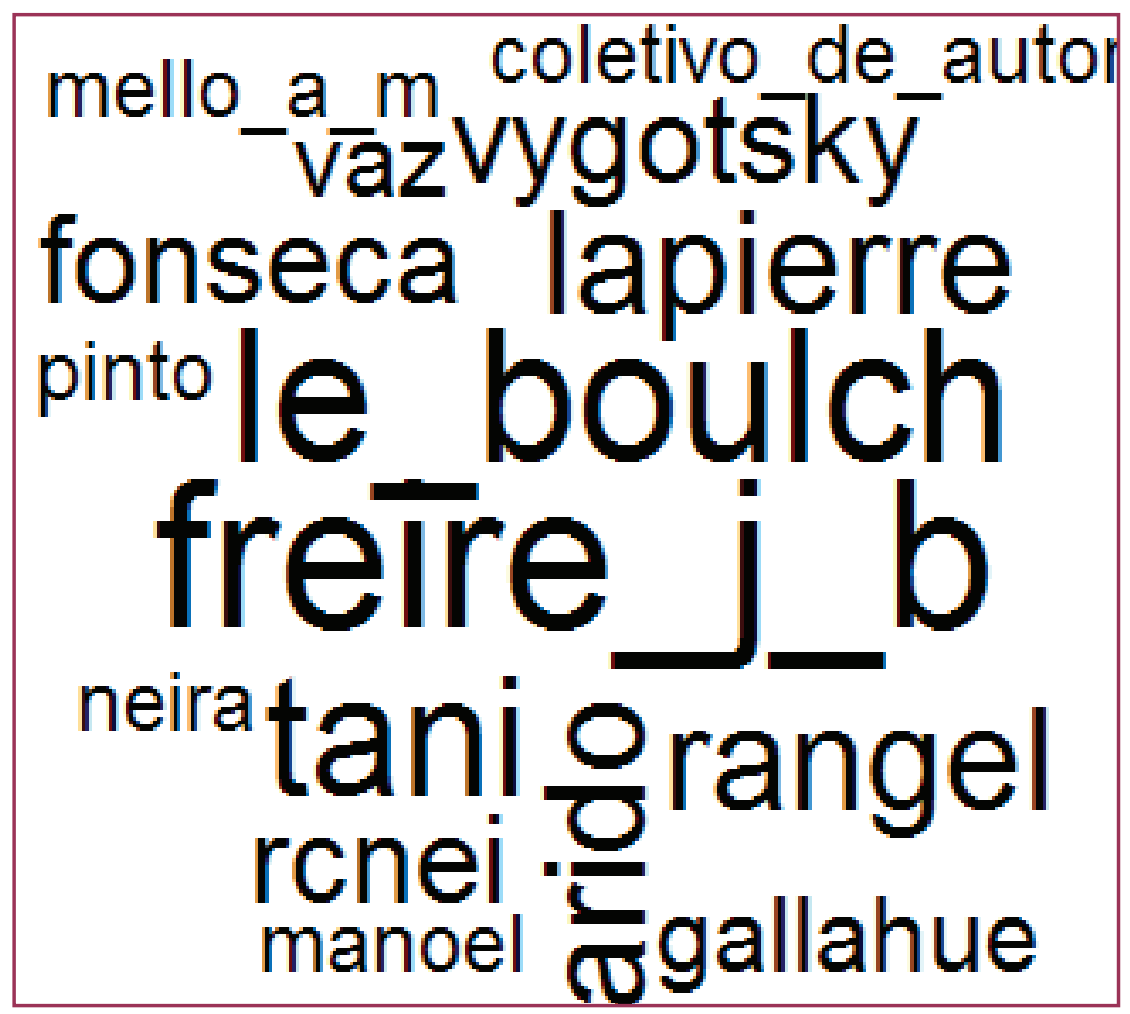

Fonte: Os autores. 
João Batista Freire e Le Boulch são os autores mais recorrentes nas bibliografias analisadas, ocupando uma posição central na nuvem de palavras e um tamanho de destaque em relação aos outros autores. Parcela significativa das produções de Freire está assentada na Psicologia Genética, de Jean Piaget. Essa proposta apresenta contribuições relativas ao desenvolvimento infantil, principalmente do ponto de vista da cognição. Todavia, ela está atrelada a uma concepção de corpo/movimento como meio para alcançar as aprendizagens valorizadas pela cultura escolar, nesse caso, a leitura, a escrita e o raciocínio lógico-matemático.

Já a Psicomotricidade de Le Boulch (1986), também assumida por Lapierre (1986; 1996) e Fonseca (1999), advoga por uma ação educativa a partir dos movimentos espontâneos da criança e das atitudes corporais, favorecendo a gênese da imagem do corpo, núcleo central da personalidade. A educação psicomotora, defendida por esses autores, refere-se à formação de base indispensável a toda criança, seja ela considerada normal ou com necessidades especiais, e responde a uma dupla finalidade: assegurar o desenvolvimento funcional, considerando a possibilidade da criança se desenvolver em sua afetividade a expandir-se; e a equilibrar-se, por meio da interação com o ambiente natural e social. Esses autores estão relacionados ao bloco temático Dimensão Conceitual do Conhecimento, em que seus pressupostos configuram como conhecimentos a serem adquiridos para a prática docente na Educação Infantil.

Go Tani é outro autor que se destaca na nuvem de palavras. Ele, em parceria com Manoel, Kokubun e Proença, escreveu o livro Educação Física Escolar: fundamentos de uma abordagem desenvolvimentista (1988), que preconiza a aprendizagem de habilidades motoras compatíveis com a fase do desenvolvimento motor em que a criança se encontra. Gallahue (1996) também se destaca na nuvem. Ele se caracteriza como um autor partidário dos princípios desenvolvimentistas. Embora reconheça que o desenvolvimento motor esteja intimamente relacionado com a idade, pondera que esse processo não depende exclusivamente dela e reconhece as influências do ambiente e dos objetivos das tarefas nas quais os indivíduos (a criança) estão envolvidos. O RCNEI também aparece na nuvem. É um documento oficial, editado pelo Ministério da Educação em 1998, e reforça a visão desenvolvimentista de Educação Física, ao valorizar a aprendizagem das habilidades motoras e o desenvolvimento das capacidades físico-perceptivas. Esses referenciais dão suporte ao bloco Comportamento Motor, evidenciado na Análise de Similitudes.

Darido e Rangel (2005) e o Soares et al. (1992) ${ }^{7}$, presentes na nuvem de palavras, assumem a cultura corporal de movimento como objeto da Educação Física em suas obras. Entretanto, ainda que as dimensões social, cultural e lúdica sejam valorizadas por esses autores e que suas obras tenham impactado fortemente na Educação Física Escolar, elas não contemplam, especificamente, a Educação Infantil. Tratam, de maneira geral, dessas dimensões, que podem ser consideradas em qualquer etapa da Educação Básica, sem uma distinção clara que leve em consideração as particularidades de cada uma delas.

Vygotsky é um autor da Psicologia Sócio-Histórica presente na nuvem de palavras. Sem desconsiderar a dimensão biológica, o autor enfatiza a importância dos aspectos culturais nos processos de desenvolvimento dos indivíduos. Ao longo do percurso de desenvolvimento "[... ] 0 indivíduo toma posse das formas de comportamento fornecidas pela cultura, num processo em que as atividades externas e as funções interpessoais transformam-se em atividades internas, intrapsicológicas, portanto, particulares" (RIBEIRO; CAVASSAN, 2013, p. 21). Sarmento (2013)

7 Na nuvem, corresponde à obra denominada nas referências das disciplinas analisadas como "Coletivo de Autores". 
considera relevantes as contribuições da Psicologia do Desenvolvimento, especialmente representada por Vygotsky, no que concerne ao processo sociocultural de desenvolvimento humano, em que o papel do "outro", da cultura, se configura como pressuposto fundamental. Contudo, Mello et al. (2016) destacam que a Psicologia do Desenvolvimento se preocupa com o que ocorre "dentro" das crianças em seu desenvolvimento, mesmo que esse processo seja mediado na interação com o social. Desse modo, um olhar para o que se passa "entre" as crianças e as produções advindas das suas culturas de pares ${ }^{8}$ fica ofuscado.

Na esteira desse debate, Mello e Santos (2012) ressaltam que as práticas pedagógicas da Educação Física na Educação Infantil devem prezar pela qualidade das relações entre adultos e crianças e entre estas e seus pares, de modo a superar os modelos tradicionais de ensino que desconsideram as crianças como sujeitos de direitos, produtores de cultura e protagonistas dos seus processos de socialização.

Como visto, permeiam o centro da nuvem de palavras as concepções teóricas vinculadas à Psicologia, à Psicomotricidade e ao Comportamento Motor. Dentro de seus limites, indica que os autores provenientes desses campos despontam e protagonizam as bibliografias das disciplinas que tematizam a Educação Infantil nos currículos de licenciatura em Educação Física, em especial, naquelas destinadas a discutir e subsidiar as práticas pedagógicas. A força desses campos do conhecimento já vem sendo percebida e criticada por autores da área há algum tempo, pois apresentam um formato escolarizado de Educação Física infantil em que têm prevalecido as abordagens Psicomotoras, Desenvolvimentistas e Recreacionistas, pelas quais as crianças são concebidas como "seres universais", com princípios fixos de desenvolvimento, determinados pela maturação biológica do organismo. Calcadas em um modelo cognitivista de educação, essas perspectivas têm assumido um caráter funcionalista, no sentido de promover condições favoráveis para que as aprendizagens consideradas importantes, em especial a leitura e a escrita, se efetivem (ASSIS, 2015; KLIPPEL, 2013; MARTINS; SCOTTÁ; MELLO, 2016).

As palavras Educação Infantil, Desenvolvimento, Criança, Motor, Habilidade, Conhecimento e Corporal, aliadas à bibliografia em que prevalecem autores ligados ao Comportamento Motor e à Psicomotricidade, oferecem o entendimento de que a relação entre Educação Física e Educação Infantil está pautada em aspectos biologicistas, em que o objetivo das aulas de Educação Física na Educação Infantil é promover suporte para futuras aprendizagens, privilegiando o desenvolvimento de habilidades motoras básicas e de funções psicomotoras. Embora sejam muito relevantes, essas concepções não consideram as potencialidades criativas das crianças e as suas produções culturais (MELLO et al., 2016). O risco dessa ênfase é uma suposta negação de outras contribuições que a Educação Física infantil pode assumir no trato pedagógico do corpo e do movimento, que vão além do aspecto motor, em consonância com a BNCC, por exemplo.

O corpo expressa e carrega consigo não somente características físicas e biológicas, mas também marcas de nosso pertencimento social que repercutem em quem somos e nas experiências que temos em relação ao gênero, à etnia ou raça, à classe, à religião e à sexualidade. 0 corpo é e revela nossa singularidade, nossa identidade pessoal e social. Com o corpo - por meio do olhar, do tato, da audição, do paladar, do olfato, das sensações, da postura, da mímica, dos movimentos impulsivos ou coordenados, dos gestos - as crianças, desde bebês,

8 Corsaro $(2009$, p. 32) define cultura de pares como "[...] um conjunto estável de atividades ou rotinas, artefatos, valores e interesses que as crianças produzem e compartilham na interação com seus pares". 
exploram o mundo, estabelecem relações, expressam-se, brincam e produzem conhecimentos sobre si, sobre o outro, sobre o universo social e cultural (BRASIL, 2016, p. 70).

A conexão da palavra "Atividade" com as palavras "Jogo" e "Orientação" sugere que as disciplinas curriculares acerca das práticas pedagógicas privilegiam o jogo como principal conteúdo de ensino. Baseados nos autores de maior destaque na "nuvem" dessas disciplinas (Le Boulch, Freire, Tani, Fonseca, Gallahue e RCNEI), expressa na Imagem 3, deduzimos que o jogo é tomado como meio, ou seja, como uma estratégia metodológica para a aprendizagem e/ou desenvolvimento de habilidades, que valoriza os aspectos motores.

Sobre essa questão, optamos por discutir com base em Freire e no RCNEl. Na abordagem Construtivista (FREIRE, 1989), assentada na Psicologia da aprendizagem e do desenvolvimento, os jogos e os brinquedos fazem parte da cultura infantil e são considerados como facilitadores do desenvolvimento e não como "parte da cultura humana", é o meio e não fim no processo educacional utilizado pela Educação Física. O RCNEl, por sua vez, ressalta que as instituições escolares de atendimento à infância:

[...] devem assegurar e valorizar, em seu cotidiano, jogos motores e brincadeiras que contemplem a progressiva coordenação dos movimentos e o equilíbrio das crianças. Os jogos motores de regras trazem também a oportunidade de aprendizagens sociais, pois, ao jogar, as crianças aprendem a competir, a colaborar umas com as outras, a combinar e a respeitar regras (BRASIL, 1998, v. 3, p. 35).

Nota-se também que a palavra criança encontra-se mais próxima da extremidade da "nuvem", indicando pouca ênfase dada a ela pelas ementas. Temos a hipótese de que há uma secundarização do sujeito da aprendizagem, justamente nas disciplinas que focalizam as práticas pedagógicas, que não ocorrem sem a presença e a interação com a criança. No curso do amadurecimento da área, a BNCC reafirma a premissa que consta nas DCNEI de que toda mediação pedagógica na primeira etapa da Educação Básica precisa observar a "centralidade da criança" nos processos de ensino-aprendizagem.

A apropriação e a construção de conhecimentos pelas crianças nas instituições de Educação Infantil, urbanas e rurais, efetivam-se pela participação delas em diferentes práticas culturais, intencionalmente organizadas pelo professor e pela professora, no cotidiano das unidades nas quais interagem com parceiros/as adultos e companheiros/as de idade (BRASIL, 2016, p. 55).

A diluição da palavra "criança" pode ser considerada um indício de que esses pressupostos não estão sendo considerados pelas ementas das disciplinas que discutem as práticas pedagógicas da Educação Física com a Educação Infantil. A secundarização da palavra "criança" nas ementas que tratam das práticas pedagógicas, somada à ênfase nos processos de organização didático-pedagógica, remete à comum confusão do papel da criança com 0 de aluno. Assim, as crianças passam a ser observadas e problematizadas a partir de sua participação nos seus processos de inserção escolar, muito em função de a escola ser socialmente aceita como a ocupação principal da infância (SIROTA, 2001).

O entendimento de criança presente nas DCNEI, reafirmado na BNCC, preconiza as crianças como sujeitos de direitos, produtoras de cultura e protagonistas dos seus processos de socialização (BRASIL, 2013). Essa vertente implica o reconhecimento da capacidade de produção simbólica por parte das crianças e a constituição das suas representações e crenças em sistemas organizados, isto é, em culturas. 
Notamos a ausência, na nuvem de palavras e na análise de similitudes, de palavras como brincar/brincadeiras, pois, como define a própria BNCC, o brincar é um dos direitos de aprendizagem e desenvolvimento estabelecido pelo referido documento. Para Mello et al. (2016), tanto os jogos quanto as brincadeiras são eixos centrais dos processos pedagógicos desenvolvidos na Educação Infantil e são eles, justamente, os que estabelecem maior interface entre a Educação Física e a Educação Infantil, considerando que a primeira etapa da Educação Básica não se organiza de maneira disciplinar.

Cabe assinalar, também, as ausências de palavras como "experiência" e "linguagens", tendo em vista que a BNCC propõe a integração curricular na Educação Infantil por meio dos "campos de experiências", entendidos como "[...] um conjunto de práticas que articulam os saberes e os fazeres das crianças com os conhecimentos já sistematizados pela humanidade" (BRASIL, 2016, p. 21). As diferentes linguagens (motora, afetiva, artística, oral, escrita etc.) presentes no contexto da Educação Infantil são compreendidas como os saberes e fazeres que devem ser trabalhados pedagogicamente com as crianças no sentido de serem "[...] intencionalmente voltadas para as experiências concretas da vida cotidiana, para a aprendizagem da cultura, pelo convívio no espaço da vida coletiva e para a produção de narrativas individuais e coletivas" (BRASIL, 2013, p. 93).

\section{CONSIDERAÇÕES FINAIS}

Muitos são os desafios para a afirmação da Educação Física na Educação Infantil, especialmente aqueles relacionados com a mediação pedagógica dessa área de conhecimento em consonância com as concepções de infância e de criança estabelecidos nos documentos legais/pedagógicos que orientam o trabalho educativo com crianças de zero a cinco anos de idade.

Neste artigo, de modo geral, percebemos um afastamento do conteúdo das ementas e das bibliografias das 16 disciplinas analisadas com relação à produção acadêmica e com os documentos oficiais que balizam o trabalho pedagógico na Educação Infantil no país. Esse distanciamento pode acarretar dificuldades para a ampliação e, até mesmo, a permanência do professor com formação em Educação Física na primeira etapa da Educação Básica, na medida em que os indícios captados nesses dados divergem frontalmente das concepções de infância/criança, de corpo/movimento e de jogos/brincadeiras trazidas, tanto na BNCC quanto nas DCNEl.

Se, em tese, a formação inicial "prepara" o sujeito para atuar em um determinado viés teórico-metodológico, uma possibilidade de reversão desse quadro é de que os docentes, ao iniciarem sua trajetória na Educação Infantil, possam reconstruir, por meio dos "saberes da experiência" (TARDIF, 2007), sua atuação profissional de maneira mais alinhada com uma concepção de infância que traga a criança para o centro da ação pedagógica e que a mediação se dê, fundamentalmente, pelas experiências decorrentes das relações estabelecidas entre as crianças e delas com os adultos, evitando, assim, a assunção de perspectivas que desconsiderem as singularidades da infância, as expectativas e necessidades das crianças. Para isso, o trabalho pedagógico da Educação Física precisa estar lastreado na interlocução com os outros "saberes-fazeres" (ALVES, 2010), privilegiando o intercâmbio entre as áreas do conhecimento e entre profissionais de diferentes formações acadêmicas. 
Por outra vertente, cremos que a formação continuada também pode contribuir para a qualificação da atuação docente, oportunizando aos docentes confrontarem, questionarem e revisarem suas concepções e práticas a fim de torná-las mais adequadas às reais demandas que emanam do cotidiano escolar.

O estudo incidiu sobre documentos oficiais disponibilizados pelas instituições selecionadas mediante critério definido na metodologia. Acreditamos na seriedade dessas instituições e na prestação dessas informações, porém, cabe ressalvar que tais fontes nos impõem como limite analisar apenas a dimensão "prescrita" dessas ementas/bibliografias, impedindo-nos de assegurar que seu conteúdo, de fato, é materializado na prática pelos professores responsáveis por essas disicplinas na formação inicial.

Acreditamos que essa discussão não se esgota nas análises empreendidas neste artigo, ao contrário, necessita ser ampliada para a análise do currículo e respectivas ementas/ bibliografias de outras universidades para além daquelas situadas em capitais brasileiras, que já há a presença de professores de Educação Física atuando profissionalmente no magistério público municipal com a Educação Infantil.

\section{REFERÊNCIAS}

ALVES, Nilda. Sobre as razões das pesquisas nos/dos/com os cotidianos. In: GARCIA, Regina Leite (Org.). Diálogos cotidianos. Petrópolis, RJ: DPetAlli, 2010.p. 67-82.

ASSIS, Lívia Carvalho de. Por uma perspectiva pedagógica para intervenção da educação física com a educação infantil. 2015.181f. Dissertação (Mestrado em Educação Física) - Programa de Pós-Graduação em Educação Física, Universidade Federal do Espírito Santo, Vitória, 2015.

AYOUB, Eliane. Reflexões sobre Educação Física na Educação Infantil. Revista Paulista de Educação Física, Supl. 4, p. 53-60, 2001.

BRASIL. Ministério da Educação. Diretrizes Curriculares Nacionais Gerais da Educação Básica. Brasília: Secretaria de Educação Básica. Diretoria de Currículos e Educação Integral, 2013.

BRASIL. Ministério da Educação. Base Nacional Comum Curricular. Segunda versão. Brasília: MEC, 2016. Disponível em: <http://basenacionalcomum.mec.gov.br/\#/site/inicio>. Acesso em: 10 mar. 2017.

BRASIL. Ministério da Educação. Referencial Curricular Nacional para a Educação Infantil. Ministério da Educação e do Desporto. Secretaria da Educação Fundamental. Brasília: MEC/SEF, 1998. v. 3.

CAMARGO, Brigido Vizeu; JUSTO, Ana Maria. Tutorial para uso do software de análise textual IRAMUTEQ. Florianópolis: Laboratório de Psicologia Social da Comunicação e Cognição - LACCOS da Universidade Federal de Santa Catarina, 2013.

CAVALARO, Adriana Gentilin; MULLER, Verônica Regina. Educação Física na Educação Infantil: uma realidade almejada. Educar, n. 34, p. 241-250, maio/ago. 2009.

CHARLOT, Bernard. Da relação com o saber: elementos para uma teoria. Porto Alegre: Artmed, 2000. 
CORSARO, William A. Reprodução interpretativa e cultura de pares. In: MULLER, Fernanda; CARVALHO, Ana Maria Almeida (Org.). Teoria e prática na pesquisa com crianças: diálogos com William Corsaro. São Paulo: Cortez, 2009. p. 31-50.

DEBORTOLI, José Alfredo O. Educação física/educação do corpo/educação dos sentidos: novosvelhos e outros discursos na educação infantil. In: SCHINEIDER, Omar; ANDRADE FILHO, Nelson Figueiredo (Org.). Educação física para a educação infantil: conhecimento e especificidade. São Cristóvão/SE: Editora UFS, 2008. p. 97-121.

FREIRE, João Batista. Educação de corpo inteiro: teoria e prática da educação física. São Paulo: Scipione, 1989.

INEP. INSTITUTO NACIONAL DE ESTUDOS E PESQUISAS EDUCACIONAIS. Censo da Educação Superior 2016: principais resultados. Diretoria de Estatísticas Educacionais. Brasília, 2016. Disponível em: <http://download.inep.gov.br/educacao superior/censo superior/documentos/2016/ censo superior tabelas.pdf>. Acesso em: 23 set. 2017.

KLIPPEL, Marcos Vinícius. 0 jogo na educação física da educação infantil: usos e apropriações em um CMEI de Vitória/ES. 2013. 150f. Dissertação (Mestrado em Educação Física) - Programa de Pós-Graduação em Educação Física, Universidade Federal do Espírito Santo, Vitória, 2013.

LACERDA, Cristiane Guimarães.; COSTA, Martha Benevides da. Educação física na educação infantil e o currículo da formação inicial. Revista Brasileira de Ciências do Esporte, v. 34, n. 2, p. 327-341, abr.jun. 2012.

MARTINS, Rodrigo Lema Del Rio, SCOTTÁ, Bianca Andreatta; MELLO, André da Silva. Pibid, educação infantil e educação física: práticas pedagógicas centradas nas crianças. Nuances: estudos sobre educação, v. 27, n. 1, p. 46-66, jan./abr. 2016.

MARTINS, Rodrigo Lema Del Rio. 0 Pibid e a formação docente em Educação Física para a Educação Infantil. 2015. 167f. Dissertação (Mestrado em Educação Física) - Programa de PósGraduação em Educação Física, Universidade Federal do Espírito Santo, Vitória, 2015.

MELLO, André da Silva et al. Educação infantil e a base nacional comum curricular: interfaces com a educação física. Motrivivência, v. 28, n. 48, p. 130-149, set. 2016.

MELLO, André da Silva; SANTOS, Wagner. Educação física na educação infantil: práticas pedagógicas no cotidiano escolar. Curitiba: Editora CRV, 2012.

PINTO, Rubia-Mar Nunes. A formação de professores para a educação infantil: desafios para a universidade. Pensar a Prática, v. 4, p. 135-148, jun./jul. 2001.

RIBEIRO, Job Antônio Garcia; CAVASSAN, Osmar. As quatro dimensões da relação homem: meio ambiente. Pesquisa em Educação Ambiental, v. 8, n. 2, p. 11-30, 2013.

RICHTER, Ana Cristina; VAZ, Alexandre Fernandes. Educação física, educação do corpo e pequena infância: interfaces e contradições na rotina de uma creche. Movimento, v. 16, n. 1, p. 53-70, jan./ mar. 2010.

SARMENTO, Jacinto Manuel. A sociologia da infância e a sociedade contemporânea: desafios conceituais e praxeológicos. In: ENS, Romilda Teodoro; GARANHANI, Marynelma Camargo (Org.). Sociologia da infância e a formação de professores. Curitiba: Champagnat, 2013. p. 13-46.

SAYÃO, Debora Thomé. Educação Física na Educação Infantil: riscos, conflitos e controvérsias. Motrivivência, v. 11, n. 13, p. 221-238, 1999. 
SIROTA, Régine. Emergência de uma sociologia da infância: evolução do objeto e do olhar.

Cadernos de Pesquisa, n. 112, p. 7- 31, mar. 2001.

SOARES, Carmen Lúcia et al. Metodologia do Ensino de Educação Física. São Paulo: Cortez, 1992.

TARDIF, Maurice. Saberes docentes \& formação profissional. 8. ed. Petrópolis, RJ: Vozes, 2007. 
